\title{
Sperm Morphology of Some Indian Frogs as Revealed by SEM
}

\author{
Mitsuru KURAMOTO ${ }^{1 *}$ AND S. HAREeSh JOSHY ${ }^{2}$ \\ 1 3-6-15 Hikarigaoka, Munakata, Fukuoka 811-3403, JAPAN \\ ${ }^{2}$ Department of Zoology, St. Aloysius College, Mangalore-575 007, INDIA
}

\begin{abstract}
The size and shape of 15 species of frogs (Ranidae and Rhacophoridae) from southwestern India were investigated by light and scanning electron microscopy. Most species of the genus Rana had spermatozoa of a typical form, with a thick sperm head and a thin tail. In contrast, Rana beddomii had long spermatozoa with a slender and densely coiled sperm head and a thick tail, suggesting the validity of the genus Indirana. The sperm head of Nyctibatrachus major was thick and very loosely coiled. Differing from Rhacophorus species from east Asia, the sperm head of $R h$. malabaricus was not coiled. Polypedates maculatus had very long thread-like spermatozoa as in Rh. malabaricus. Spermatozoa of all examined species of the genus Philautus had a crescent-like sperm head and a thin tail resembling the head and tail of the genus Chirixalus.
\end{abstract}

Key words: Anura; Spermatozoa; SEM; India

\section{INTRODUCTION}

To date, spermatozoa of more than a hundred species of frogs have been investigated by light microscopy (LM), SEM or TEM (e.g., Lee and Jamieson, 1992; Kuramoto, 1998; van der Horst et al., 1995). From these studies, it became evident that sperm morphology is very variable between taxa and useful for elucidating taxonomic relationships between them. For example, Kuramoto (1996) showed that four rhacophorid genera from Japan and Taiwan have each a distinctive form of spermatozoa and, within the genus Buerger$i a$, the form of the spermatozoon of $B$. buergeri is apparently derived from the

\footnotetext{
* Corresponding author. Tel: +81-940-320730
}

sperm form of its congeners. It was also suggested that sperm morphology reflects the mode of reproduction (van der Horst et al., 1995).

India has a rich amphibian fauna, involving more than 180 species (Inger and Dutta, 1986). Among these, only two species, Bufo stomaticus and Rana tigerina, have been studied spermatologically (Sharma and Dhindsa, 1955; Sharma and Sekhri, 1955). The primary purpose of these studies was to clarify the process of spermatogenesis and thus detailed descriptions of sperm are not given.

We examined sperm morphology of several frog species from Karnataka and Kerala, southwestern India by light microscopy (LM) and scanning electron microscopy (SEM). Dubois (1992) revived several subfamilies and genera in the Rani- 
dae and his revision has induced much confusion and debate on their validity. In our present materials representatives of some of his genera are involved, and we expect that our spermatological work will provide cues to resolve this taxonomic problem. Also, we examine generic differentiation in the Rhacophoridae including the genera Philautus for which sperm morphology has not yet been reported.

\section{Materials And Methods}

Frogs used in this study were: Rana temporalis from Madikeri, Karnataka; $R$. malabarica from Cannanore, Kerala; $R$. limnocharis from Madikeri; $R$. keralensis from Madikeri; $R$. syhadrensis from Mangalore, Karnataka; $R$. cyanophlyctis from Mangalore; $R$. tigerina from Mangalore; $R$. beddomii from Madikeri; Nyctibatrachus major from Madikeri (Ranidae); Rhacophorus malabaricus from Madikeri; Polypedates maculatus from Madikeri; Philautus sp. A from Mangalore; Philautus sp. B from Mangalore; Philautus sp. C from Kudremukh, Karnataka; and Philautus sp. D from Kudremukh (Rhacophoridae). All specimens were collected in June and July 1999.

Philautus species, small arboreal frogs, are difficult to identify as Inger and Stuebing (1997, p. 163) admitted, and our specimens did not seem to fit the descriptions of Philautus species from the Western Ghats (Ahl, 1931; Daniels, 1998; Inger et al., 1984; Rao, 1937). Brief descriptions of our specimens are given here: Philautus sp. A was reddish brown on the back, some with irregular dark blotches, underside immaculate, tympanum about half of eye diameter and lower half of tympanum white, snout rather pointed, ca. $24 \mathrm{~mm}$ in SVL; Philautus sp. B was pale gray on the back with an inverted irregularly U-shaped blackish mark, underside with many scattered small dark markings, tympanum small and indistinct, snout not pointed, ca. $25 \mathrm{~mm}$ in
SVL; Philautus sp. C was dark brown on the back with a large hourglass-like pale marking from eye to vent, underside vermiculate with brown, yellow, and white, two distinct large yellowish spots on anterior surface of thigh, snout not pointed, ca. $18 \mathrm{~mm}$ in SVL; Philautus sp. D was pale yellow to reddish yellow on the back and underside including the vocal sac, some with three dark indistinct longitudinal stripes on the back, tympanum small and indistinct, ca. $26 \mathrm{~mm}$ in SVL.

We collected several other unidentified species in the genera Rana and Philautus, and we will refer to sperm morphology of these species briefly.

The testis was squashed in a small quantity of water with forceps, and the sperm suspension thus prepared was put on slides and on cover slips, fixed with $2 \%$ glutaraldehyde for about one hour, and air-dried. Spermatozoa on the slide were stained with Giemsa for LM and those on cover slips were coated with gold and observed with a scanning electron microscope JSM-T200 (JEOL). Two males were used for each species.

\section{RESUlTS}

Excepting Rana beddomii, all seven species of the genus Rana had very similar spermatozoa with a thick sperm head and a thin tail (Fig. 1). Sperm sizes were also similar, ranging from about 15 to $20 \mu \mathrm{m}$ in head length and from about 45 to $70 \mu \mathrm{m}$ in total length, but variable in head width (Table 1). The acrosome and the middle piece or neck piece were discernible externally from the head proper by their slightly narrower width. The tail was about $0.2 \mu \mathrm{m}$ in width. Three unidentified species from Mangalore and Kudremukh, apparently belonging to the Rana limnocharis complex, had spermatozoa which were similar to those of the above species.

Spermatozoa of $R$. beddomii were very long, about twice as long as those of the 

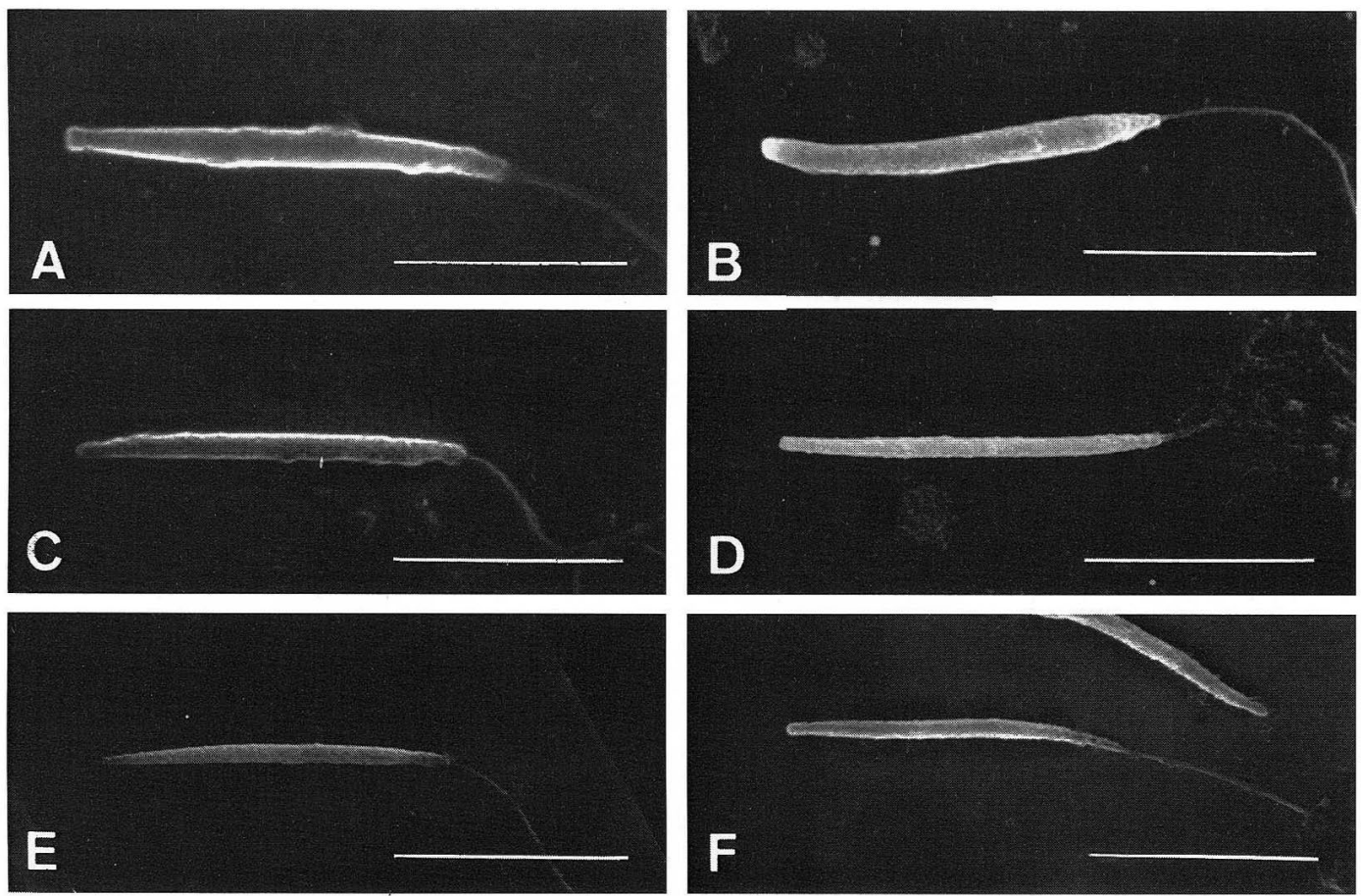

FIG. 1. Spermatozoa of Rana temporalis (A), $R$. malabarica (B), $R$. limnocharis (C), $R$. keralensis (D), $R$. syhadrensis (E), R. cyanophlyctis (F), and $R$. tigerina (G). Scales equal $10 \mu \mathrm{m}$.

other species of the genus Rana (Fig. 2, Table 1). The sperm head formed an elon- gated, densely and sinistrally coiled spiral, about $0.5 \mu \mathrm{m}$ in diameter of spiral and

TABLE 1. Sperm sizes in 15 species of frogs from southwestern India (Mean \pm SD in $\mu \mathrm{m}, \mathrm{N}=10$ ).

\begin{tabular}{lcccc}
\hline & Head length & Tail length & Total length & Head width \\
\hline Rana temporalis & $20.3 \pm 0.82$ & $45.4 \pm 3.26$ & $65.5 \pm 3.23$ & $1.7 \pm 0.10$ \\
Rana malabarica & $17.2 \pm 1.49$ & $27.9 \pm 2.78$ & $45.0 \pm 2.81$ & $1.6 \pm 0.17$ \\
Rana limnocharis & $17.4 \pm 1.28$ & $38.2 \pm 3.13$ & $55.6 \pm 3.38$ & $1.2 \pm 0.09$ \\
Rana keralensis & $16.5 \pm 0.94$ & $40.4 \pm 4.25$ & $56.9 \pm 4.67$ & $1.1 \pm 0.06$ \\
Rana syhadrensis & $18.3 \pm 2.90$ & $36.7 \pm 7.11$ & $55.0 \pm 9.16$ & $0.9 \pm 0.07$ \\
Rana cyanophlyctis & $17.0 \pm 2.05$ & $54.2 \pm 3.78$ & $71.2 \pm 4.57$ & $0.9 \pm 0.05$ \\
Rana tigerina & $15.0 \pm 1.43$ & $47.1 \pm 2.99$ & $62.1 \pm 3.67$ & $0.9 \pm 0.08$ \\
Rana beddomii & $37.5 \pm 0.90$ & $79.2 \pm 5.99$ & $116.7 \pm 6.10$ & $0.5 \pm 0.03$ \\
Nyctibatrachus major & $23.8 \pm 3.12$ & $40.1 \pm 7.11$ & $63.9 \pm 7.28$ & $0.8 \pm 0.06$ \\
Rhacophorus malabaricus & $52.3 \pm 2.44$ & $92.6 \pm 6.93$ & $144.9 \pm 5.96$ & $0.6 \pm 0.05$ \\
Polypedates maculatus & $76.5 \pm 4.20$ & $84.0 \pm 14.1$ & $160.5 \pm 14.6$ & $0.4 \pm 0.05$ \\
Philautus sp. A & $21.6 \pm 2.76$ & $28.4 \pm 4.74$ & $50.0 \pm 5.21$ & $0.8 \pm 0.05$ \\
Philautus sp. B & $23.8 \pm 2.77$ & $28.5 \pm 2.66$ & $52.3 \pm 4.38$ & $0.8 \pm 0.04$ \\
Philautus sp. C & $19.0 \pm 2.28$ & $30.9 \pm 4.88$ & $49.9 \pm 4.56$ & $0.8 \pm 0.03$ \\
Philautus sp. D & $20.6 \pm 3.39$ & $29.7 \pm 3.50$ & $50.3 \pm 3.63$ & $0.8 \pm 0.05$ \\
\hline
\end{tabular}



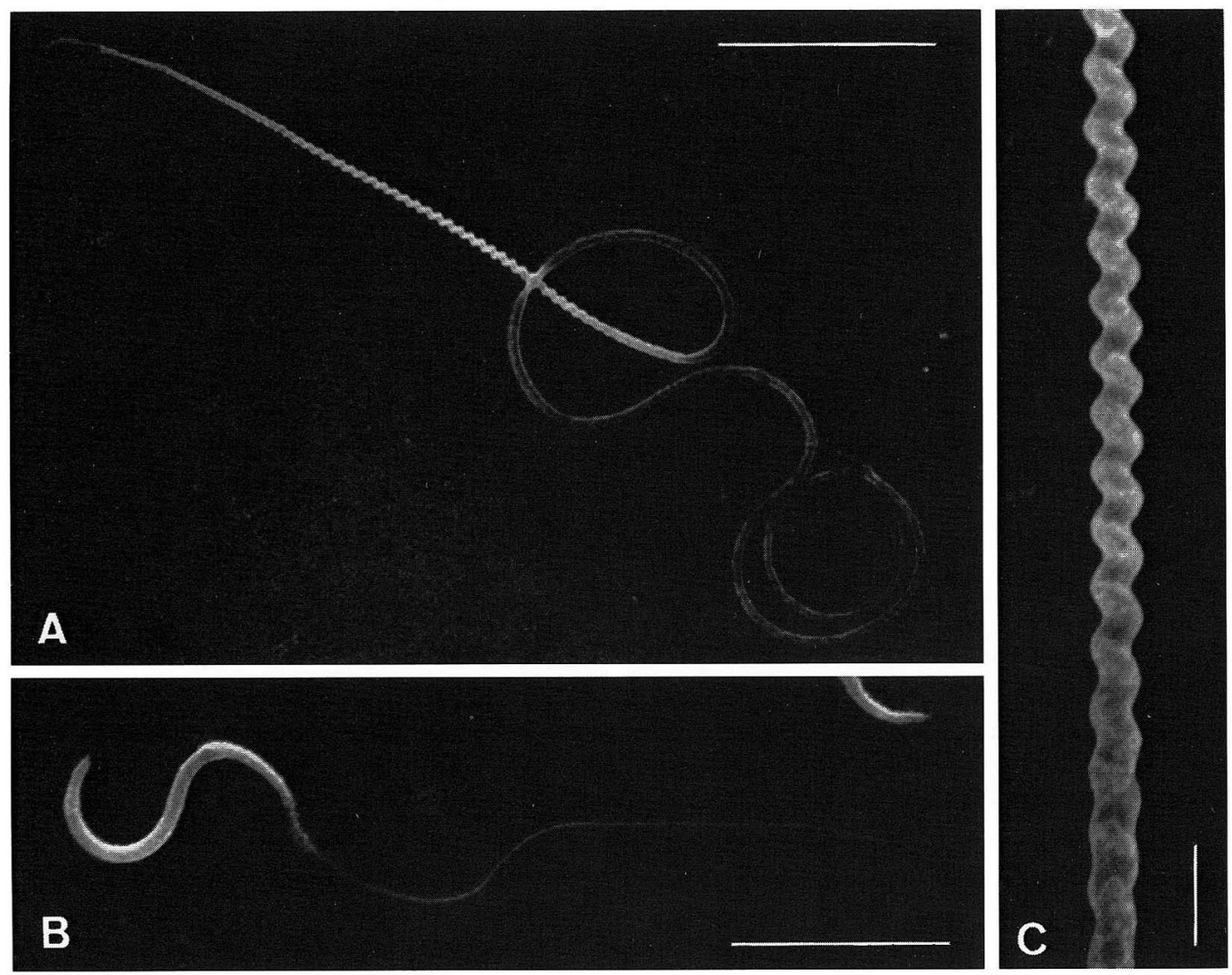

FIg. 2. Spermatozoa of Rana beddomii (A), Nyctibatrachus major (B), and a part of the coiled sperm head of $R$. beddomii (C). The lower part of the coil in (C) is the basal portion of the head. Scales equal $10 \mu \mathrm{m}$ in (A) and (B), and $1 \mu \mathrm{m}$ in (C).

about $0.3 \mu \mathrm{m}$ in width of coil fiber. "Head length" of $R$. beddomii in Table 1 shows the length of the coil, not the net length of coil fiber. The tail width (about $0.5 \mu \mathrm{m}$ ) was nearly the same as head width and much wider than those of its congeners. This type of spermatozoa is new to our knowledge of anuran sperm morphology. We examined the sperm of a frog from Madikeri which was similar to $R$. beddomii but could not be precisely identified. This frog had spermatozoa which were nearly identical to those of $R$. beddomii. The testis of $R$. beddomii and the unidentified beddomii-like frog was considerably larger than that of the other ranid frogs.

Nyctibatrachus major had also peculiar spermatozoa (Fig. 2). Typically the sperm head was S-shaped, undoubtedly forming a loose coil three-dimentionally. A slightly thin portion at the tip of head may be the acrosome and that at the end may be the middle piece. The tail was $0.13 \mu \mathrm{m}$ in width, much thinner than most species of the genus Rana. Total sperm length was within the range of most Rana species. This type of spermatozoa has not been reported in Ranidae. The testis was much smaller than in most ranid species.

Rhacophorus malabaricus had long thread-like spermatozoa, and Polypedates maculatus had still longer ones (Fig. 3, Table 1). The acrosome and the middle piece could not be distnguished externally in 

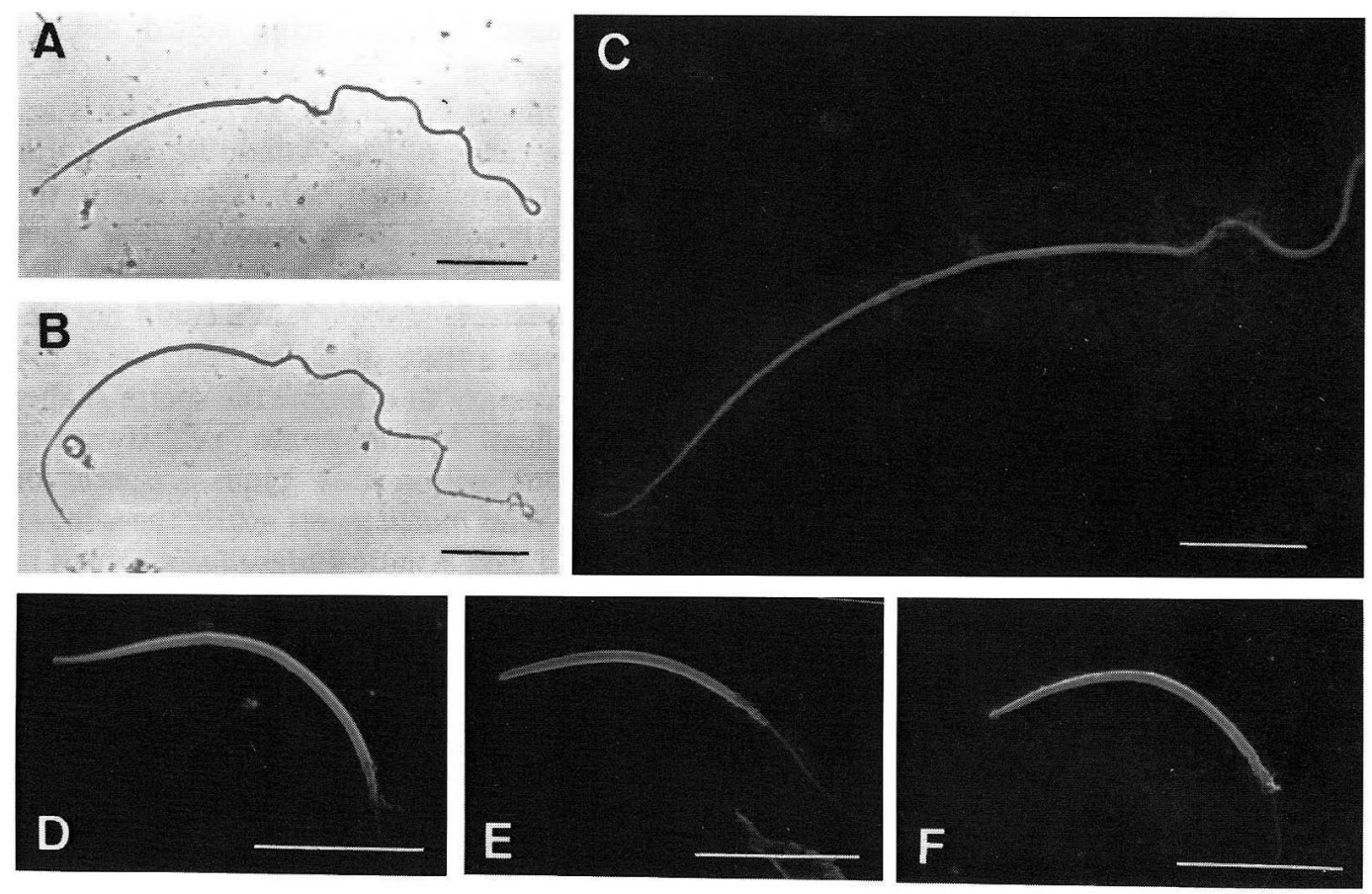

FIg. 3. Spermatozoa of Rhacophorus malabaricus (A, C), Polypedates maculatus (B), Philautus sp. A (D), Philautus sp. B (E), and Philautus sp. D (F). (A) and (C) were taken by LM. Scales equal $20 \mu \mathrm{m}$ in (A) and (B), and $10 \mu \mathrm{m}$ in (C)-(F).

either species. The tail was thick, only slightly thinner than the sperm head with a width of about 0.4 to $0.5 \mu \mathrm{m}$.

The four species of the genus Philautus had spermatozoa of nearly the same size as those in the genus Rana (Table 1). The sperm head was invariably bent slightly, forming a crescent (Fig. 3). The middle piece was granular in appearance. The tail was thin, about $0.2 \mu \mathrm{m}$ in width. We examined sperm of three other species of Philautus (unidentified) and all were very similar to that of the above four species in every characteristic.

\section{DISCUSSION}

Sperm shape and size of the seven species of the genus Rana examined in this study (temporalis, malabarica, limnocharis, keralensis, syhadrensis, cyanophlyctis, tigeri- na) are essentially identical to those of the other Rana species reported so far, in that all have a thick sperm head and a thin tail (Kuramoto, 1998; van der Horst et al., 1995). The sperm form of $R$. tigerina agrees well with the description by Sharma and Sekhri (1955). The sperm head of $R$. limnocharis is much longer than that of the same species from Japan and China (Kuramoto, 1998), suggesting intraspecific geographic variations in sperm size as exemplified in Japanese salamanders (Kuramoto, 1997). Noticeable exceptions in the genus Rana were three species of the Rana narina complex and $R$. ishikawae which had very long, slender spermatozoa (Kuramoto, 1998).

Rana beddomii had a completely different type of sperm which was unlike any other sperm type found in anurans. The sperm head is long and densely coiled, and the tail 
is thick suggesting involvement of filamentous components other than a single flagellum. Detailed TEM analysis is needed to clarify this unusual feature of sperm. In the Rana species here examined, limnocharis, keralensis, and syhadrensis are frequently allocated to the genus Limnonectes, cyanophlyctis to the genus Euphlyctis, tigerina to the genus Hoplobatrachus (as H. tigerinus), and beddomii to the genus Indirana (Duellman, 1993; Dutta and Manamendra-Arachchi, 1996). The genera Limnonectes, Euphlyctis, and Hoplobatrachus do not show any sign of sperm differentiation as already pointed out by Kuramoto (1998) in Limnonectes and Hoplobatrachus, whereas Indirana differs completely from other genera in sperm type, indicating a different phyletic lineage. The karyotype of $R$. beddomii $(2 n=24$, Joshy et al., 1999) also differs from the other Indian ranid frogs. These suggest strongly the validity of the genus Indirana. It should be confirmed whether the other species which are allocated to Indirana have the same sperm type.

The sperm head of Nyctibatrachus major was very loosely coiled. The sperm shape of Xenopus laevis (Bernardini et al., 1986, 1988; Yoshizaki, 1987) resembles that of $N$. major. Some pelobatid frogs, Megophrys montana (Asa and Phillips, 1988) and four species of Vibrissaphora (Wu and Yang, 1981) have spermatozoa which are coiled several times. According to Asa and Phillipps (1988), chromatin condenses to form a cylindrical coil within a spherical nucleus of spermatids without participation of microtubular manchette. The occurrence of this sperm type in several unrelated anuran families suggests a common cytological basis for shaping this loosely coiled sperm head. The coil structure of the sperm head found in $R$. beddomii and Rhacophorus species inhabiting east Asia may also have the same basis. All types of coiled sperm head reported so far are coiled sinistrally, and this also suggests a common underlying mechanism for producing coiled nuclear condensation.

The sperm size of $R h$. malabaricus is within the range of east Asiatic Rhacophorus species (Kuramoto, 1996). Contrary to the compactly coiled sperm heads of these other species, however, the sperm head of $R h$. malabaricus is straight. We could not observe even a trace of coiled structure at all. It is necessary to examine the sperm shapes of southeast Asiatic species to clarify sperm variations within this genus. Sperm of Polypedates maculatus is nearly the same as those of east Asiatic Polypedates species in both shape and size.

The crescent-like sperm heads of the genus Philautus are very similar to those of Chirixalus species from east Asia (Kuramoto, 1996), suggesting a close relationship of the two genera. The relationship from spermatological data fits the phylogeny of Channing (1989) fairly well, but not that of Liem (1970). This shape of sperm head may link straight and loosely coiled types.

Van der Horst et al. (1995) suggested a correlation between sperm size and the mode of fertilization in South African frogs, that is, terrestrial fertilizers have long spermatozoa and aquatic fertilizers short ones. Kuramoto (1998), examining his spermatological data, doubted this tendency. In the present materials, we observed that a $R$. beddomii-like frog lays eggs in seepages often exposed directly to the air and the eggs were enveloped with tough gelatinous coats. This mode of reproduction is not purely aquatic, so the longer sperm of $R$. beddomii seems to fit the tendency of van der Horst et al. (1995). However, sperm of $R$. tagoi of Japan which has a similar mode of reproduction and the same kind of gelatinous envelope does not differ from that of the other aquatic fertilizers (Kuramoto, 1998). The terrestrial reproductive mode of Rhacophorus and Polypedates seems to agree with the tendency, but that of Philautus seems to contradict it. Although direct development in Philau- 
tus was reported in species of Philippines (Alcala and Brown, 1982) and Malaysia (Yong et al., 1988) and not in Indian species, Inger et al. (1984) collected most of their Philautus specimens from places far from any stream or pond. We also collected calling male specimens in forests or bushes usually far from water. These suggest a terrestrial mode of reproduction, but sperm of Philautus are short. Rao (1937) described larvae of some Philautus species from streams of Kempholey, Hassan, Karnataka. All have a flattened body, a long muscular tail with a low tail fin, and large mouth parts; all are characteristics of stream-dwelling larvae. No information about reproduction of Indian Philautus are available, however. The presence of freeliving aquatic tadpoles does not necessarily mean aquatic egg laying. The sperm size does not seem to relate directly to the mode of reproduction but seems to reflect phylogenetic relationships fairly well.

\section{ACKNOWLEDGMENTS}

We thank $Y$. Nagayama and $K$. Watanabe for SEM facilities, S. Rao, K. P. Siju, P. Salins and S. Babu for aid in field collecting, and Y. Shibata for literature.

\section{Literature Cited}

Ahr, E. 1931. Das Tierreich. Amphibia, Anura III, Polypedatidae. Walter de Gruyter, Berlin. $477 \mathrm{p}$.

Alcala, A. C. AND W. C. Brown. 1982. Reproductive biology of some species of Philautus (Rhacophoridae) and other Philippine anurans. Phil. J. Biol. 11: 203-226.

AsA, C. S. AND D. M. Phillipps. 1988. Nuclear shaping in spermatids of the Thai leaf frog Megophrys montana. Anat. Rec. 220: 287290.

Bernardini, G., F. Andrietti, M. Camatini AND M.-P. Cosson. 1988. Xenopus spermatozoon: correlation between shape and motility. Gamete Res. 20: 165-175.

Bernardini, G., R. Stipani and G. Melone. 1986. The ultrastructure of Xenopus sper- matozoon. J. Ultrastruct. Mol. Struct. Res. 94: 188-194.

Channing, A. 1989. A re-evaluation of the phylogeny of Old World treefrogs. S. Afr. J. Zool. 24(2): 116-131.

Daniels, R. J. R. 1998. A Field Guide to the Frogs and Toads of the Western Ghats: India. Private circulation. $72 \mathrm{p}$.

Dubors, A. 1992. Notes sur la classification des Ranidae (Amphibiens Anoures). Bull. Mens. Soc. Linn. Lyon 61: 305-352.

Duellman, W. E. 1993. Amphibian Species of the World: Additions and Corrections. Univ. Kansas Mus. Nat. Hist. Special Publ. No. 21, Univ. Kansas, Lawrence. 372 p.

Dutta, S. K. AND K. Manamendra-ArachChI. 1996. The Amphibian Fauna of Sri Lanka. Wildlife Heritage Trust of Sri Lanka, Colombo. 230 p.

INGER, R. F. AND S. K. DUtTA. 1986. An overview of the amphibian fauna of India. J. Bombay Nat. Hist. Soc. 83 (Suppl.): 135-146. INGER, R. F., H. B. SHAFFER, M. KOSHY AND R. BAKDE. 1984. A report on a collection of amphibians and reptiles from the Ponmudi, Kerala, south India. J. Bombay Nat. Hist. Soc. 81(3): 551-570.

INGER, R. F. AND R. B. Stuebing. 1997. A Field Guide to the Frogs of Borneo. Natural History Publication, Kota Kinabalu. 205 p.

Joshy, S. H., M. A. Rahiman, K. S. SReepada AND M. E. Gururaj. 1999. Karyotypes of six species of anurans from the Western Ghats, south India. Nucleus 42(1/2): 73-78.

KuRAmoto, M. 1996. Generic differentiation of sperm morphology in treefrogs from Japan and Taiwan. J. Herpetol. 30(3): 437-443.

Kuramoto, M. 1997. Further studies on sperm morphology of Japanese salamanders, with special reference to geographic and individual variation in sperm size. Jpn. J. Herpetol. 17(1): 1-10.

Kuramoto, M. 1998. Spermatozoa of several frog species from Japan and adjacent Regions. Jpn. J. Herpetol. 17(3): 107-116.

LEE, M. S. Y. AND B. G. M. JAMieson. 1992. The ultrastructure of the spermatozoa of three species of myobatrachid frogs (Anura, Amphibia) with phylogenetic considerations. Acta Zool. 73(4): 213-222.

LIEM, S. S. 1970. The morphology, systematics, and evolution of the Old World treefrogs. Fieldiana: Zool. 57: 1-145.

Rao, C.R.N. 1937. On some new frogs of 
Batrachia from S. India. Proc. Indian Acad. Sci. (B) 6: 387-427.

Sharma, G. P. AND K. S. Dhindsa. 1955. Amphibian spermatogenesis II. The sperm of toad. Res. Bull. Panjab Univ. 82: 175-187. +4 pls.

Sharma, G. P. AND K. K. SeKhri. 1955. Amphibian spermatogenesis I. The sperm of frog. Res. Bull. Panjab Univ. 79: 145-158. +4 pls. VAN DER Horst, G., B. Wilson and A. ChanNING. 1995. Amphibian sperm: phylogeny and fertilization environment. p. 333-342. In: B. G. M. Jamieson, J. Ausio, and J.-L. Justine (eds.), Advances in Spermatozoal Phylogeny and Taxonomy. Editions du Museum National d'Histoire Naturelle, Paris.
WU, G.-F. AND W.-M. YANG. 1981. Studies on genus Vibrissaphora (Amphibia: Pelobatidae) 2. Some ecological notes of vibrissaphorids. Acta Herpetol. Sinica 5(12): 77-80. (In Chinese with English abstract)

Yong, H. S., C. K. NG AND R. IsmaIl. 1988. Conquest of the land: direct development in a Malaysian Philautus tree frog. Nature Malaysiana 13: 4-7.

YoshIZAKI, N. 1987. Isolation of spermatozoa, their ultrastructure, and their fertilizing capacity in two frogs, Rana japonica and Xenopus laevis. Zool. Sci. 4: 193-196.

Accepted: 22 April 2000 